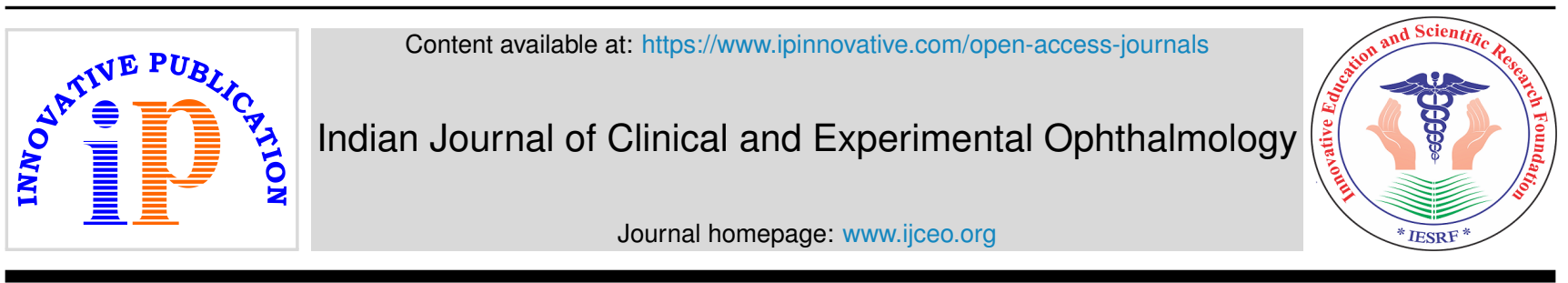

Original Research Article

\title{
Aqueous humor pharmacokinetics of Benzalkonium chloride free bimatoprost formulated in tight junction modulation technology compared to Benzalkonium chloride preserved bimatoprost $0.01 \%$ ophthalmic solution in rabbit eyes
}

\author{
Arindam Halder ${ }^{1}$, Vinod Burade ${ }^{2}$, Ajay J Khopade ${ }^{1, *}$, Monali Vakharia ${ }^{3}$ \\ ${ }^{1}$ Formulation Development, Sun Pharmaceutical Industries Limited, Vadodara, Gujarat, India \\ ${ }^{2}$ Dept. of Pharmacology, Sun Pharmaceutical Industries Limited, Vadodara, Gujarat, India \\ ${ }^{3}$ Sun Pharma Laboratories Ltd, Mumbai, Maharashtra, India
}

\section{A R T I C L E I N F O}

\section{Article history:}

Received 21-12-2020

Accepted 26-12-2020

Available online 30-06-2021

\section{Keywords:}

Aqueous humor

Bimatoprost $0.01 \%$

Gel free reservoir technology

Glaucoma

Pharmacokinetics

Polyhexamethylene biguanide

Tight junction modulator

\begin{abstract}
A B S T R A C T
Purpose: This study was undertaken with an objective to compare the aqueous humor pharmacokinetics (PKs) of bimatoprost and bimatoprost free acid of innovator bimatoprost $0.01 \%$ (BAK-Bimatoprost) and the novel formulation, Tight Junction Modulation technology based bimatoprost $0.01 \%$ (TJM-bimatoprost) containing polyhexamethylene Biguanide hydrochloride (PHMB) as a preservative.

Materials and Methods: All animals in the study were assigned to one of two treatment arms: either a single dose of BAK-Bimatoprost $(n=28)$ or a TJM-bimatoprost ophthalmic solution $(n=28)$. Time points for aqueous humor collection were $0.5,1,2,4,8,12$ and 24 Hrs after drug administration.

Results: The mean Cmax of $11.93 \pm 2.70$ vs $10.92 \pm 3.84 \mathrm{ng} / \mathrm{ml}$ was comparable ( $>>0.05$, one-way ANOVA) across TJM bimatoprost and BAK-bimatoprost treatment arms. Results of other PK parameters pertaining to bimatoprost+ bimatoprost free acid concentration were as follows: time to maximum concentration (T_max) was $1.75 \pm 2.0 \mathrm{vs} 1.50 \pm 1.16 \mathrm{hr}$ and half-live (T_half) was $2.13 \pm 0.58$ vs 2.47 $\pm 0.79 \mathrm{hr}$ in the TJM- bimatoprost and BAK-bimatoprost treatment arms respectively. Overall, there was no difference between TJM-bimatoprost and BAK-bimatoprost treatment arms in the PK end points.

Conclusions: The results taken in totality support the hypothesis that pharmacokinetics TJM-bimatoprost $0.01 \%$, containing PHMB preservative, is comparable to BAK-bimatoprost $0.01 \%$.

Key messages: A new formulation of bimatoprost $0.01 \%$ using Tight Junction Modulation technology is pharmacokinetically comparable to marketed formulation of bimatoprost containing benzalkonium chloride preservative.

(C) This is an open access article distributed under the terms of the Creative Commons Attribution License (https://creativecommons.org/licenses/by/4.0/) which permits unrestricted use, distribution, and reproduction in any medium, provided the original author and source are credited.
\end{abstract}

\section{Introduction}

Intra-ocular pressure (IOP) lowering is one of the most effective strategies to control glaucoma, which is the third leading cause of blindness worldwide ${ }^{1}$ and has prevalence rate of $3.5 \%$ in the adult Indian population. ${ }^{2}$ Anti-glaucoma medications lower IOP by either decreasing the aqueous humor production or increasing the outflow via trabecular meshwork or through the Schlemm's canal. ${ }^{3}$ Bimatoprost, a prostaglandin (PG)- F2 $\alpha$ analogue approved by the United

\footnotetext{
* Corresponding author.

E-mail address: ajay.khopade@ sunpharma.com (A. J. Khopade).
}

States Food and Drug Administration (US FDA) in 2011, is one among the first-line agents that are commonly prescribed to treat primary open angle glaucoma. ${ }^{4,5}$

Out of the two strengths of bimatoprost that are currently available, the initial formulation was marketed as Lumigan ${ }^{\circledR}$ $0.03 \%$ (Allergan, CA, USA), containing $50 \mathrm{ppm}(0.005 \%)$ of benzalkonium chloride (BAK). Although robust efficacy has been demonstrated in clinical trials, ${ }^{6}$ there are reports suggestive of increased ocular surface disease adverse events. $^{7}$ These adverse events included- eye irritation, increased iris pigmentation, distichiasis and conjunctival hyperaemia, all of which have been linked to class action 
on PG-F2 $\alpha$ receptors. ${ }^{8}$ Taking this into account, a reduced strength of Bimatoprost $0.01 \%$ was developed. In order to overcome reduced efficacy, if any, because of the decreased strength, the concentration of BAK was increased 4-folds to $200 \mathrm{ppm}(0.02 \%)$ to improve permeation into ocular tissue. $\mathrm{BAK}$ is a cationic preservative known to widen the cellto-cell tight junction in cornea and conjunctiva, resulting in increased penetration and aqueous humor concentration of the active drug. ${ }^{9}$ This reduced strength formulation was tested in a multi-centre, randomized, 12-week clinical trial that showed similar efficacy at most time points, and favorable safety profile compared to Bimatoprost $0.03 \% .{ }^{10}$

Although increasing BAK leads to higher ocular penetration it comes at a cost of side effects. BAK, a quaternary ammonium compound, is a preservative added to ophthalmic formulations to prevent infection due to contamination of multidose eye drops, as a consequence of exposure to ambient air or direct finger contact during the instillation process. On the negative side, its detergent property results in shredding of the lipid barrier in the tear film leading to evaporation of the aqueous layer due to increased exposure. ${ }^{9}$ Additionally, non-clinical studies have shown proapoptotic changes on conjunctival cell lines, decrease in antioxidants, increase in inflammatory mediators in lens epithelial cells and DNA damage. ${ }^{11,12}$ Importantly, in clinical settings, tear film disruption ascribable to BAK's detergent effect leads to increased ocular surface side effects, such as conjunctival hyperaemia, eye irritation, pruritis, dry eye and punctate keratitis, and these effects are shown to be dose dependent. ${ }^{13,14}$

Newer preservatives developed to overcome disadvantages with BAK some have shown to decrease ocular surface disease index scores. ${ }^{9}$ The efficacy outcomes have also been encouraging as the results are similar to the BAK containing innovator formulation. In this context, Sun Pharma Advanced Research Company (SPARC) has developed a newer Bimatoprost $0.01 \%$ ophthalmic solution containing an alternative preservative, Polyhexamethylene Biguanide hydrochloride (PHMB) $(0.005 \%)$. This new drug delivery system is based on proprietary gel free reservoir (GFR) and transient Tight Junction Modulation (TJM) technology (Figure 1). TJM technology improves corneal retention and permeation and are made up of two molecule, namely, 1) TJM-1, a negatively charged surfactant, can solubilize claudin and phosphorylate proteins in the tight junctions, ${ }^{15,16}$ 2) TJM-2, a positively charged polymeric molecule, which increases the fluidity of the membrane and delays claudin remodelling, ${ }^{17}$ ultimately leading to better permeation of the drug. ${ }^{18}$ In the GFR technology, there are two polymers, which increases the mean residence time and provides lubrication as well. Therefore, the two complementary technologies i.e. GFR and TJM, provide benefit by improving ocular permeation and safety compared to BAK.
The preservatives in the formulation are PHMB and sodium lauryl sarcosine. Chemically, PHMB, is a biguanide polymer and used in several antimicrobial preparations, as an excipient in cosmetic preparations, antiseptic in wound healing and orthopedic surgery and as a contact lens cleansing solution. ${ }^{19}$ For its ophthalmic use, use of PHMB was approved by European Medicines Agency (EMEA) in 2007 for Acanthamoeba keratitis. ${ }^{20}$ On the other hand, sodium lauryl sarcosine is an established copreservative in ophthalmology drug delivery systems. ${ }^{21}$ However, the described the novel formulation has not been studied in animal models. Therefore, this study was undertaken with an objective to compare the aqueous humor PKs of bimatoprost and bimatoprost free acid of innovator bimatoprost $0.01 \%$ (BAK-Bimatoprost) and the novel formulation, TJM- bimatoprost $0.01 \%$ (TJMbimatoprost) containing PHMB as a preservative.

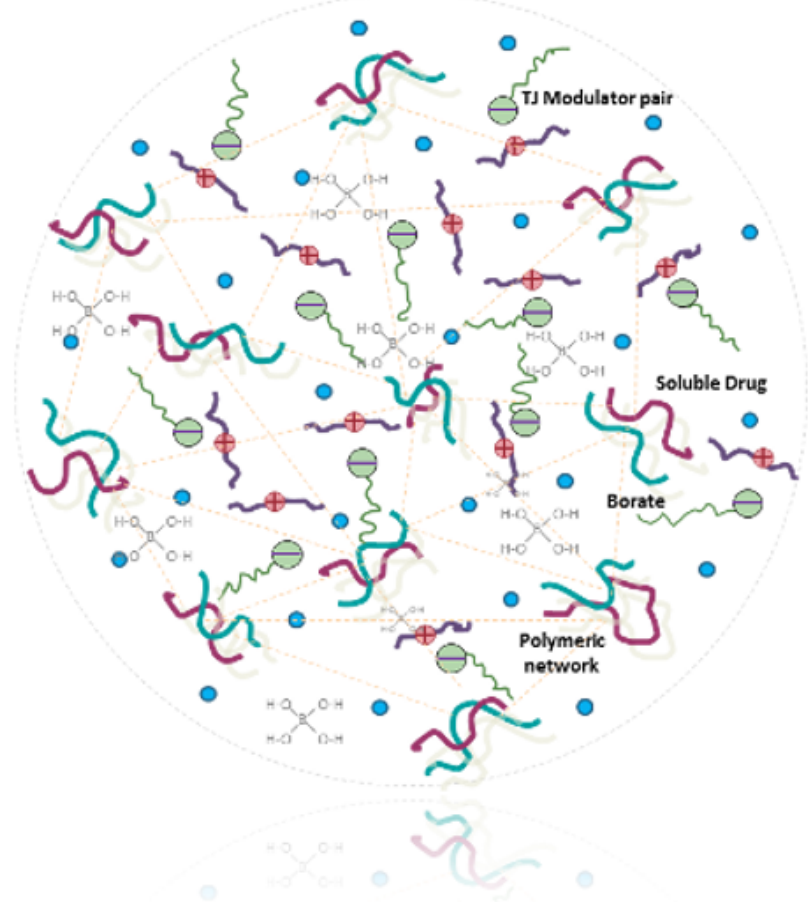

Fig. 1:

\section{Materials and Methods}

The proposed study conformed to all the guidelines and recommendations laid down by the Committee for the Purpose of Control and Supervision of Experiments on Animals (CPCSEA), ${ }^{22}$ a statutory body for overseeing ethics pertaining to animal research and permission from the institutional Ethics committee was obtained. Fifty-six New Zealand rabbits (50 male and 6 females), supplied from the laboratory animal resources at SPARC Ltd, were included in this study. The animals inbred at the SPARC's laboratory 
had an age ranging from 5 to 8 months and weight between 2.7 and $4.3 \mathrm{kgs}$. Standard animal husbandry practices were followed: housing of one animal per cage, $20-26^{\circ} \mathrm{C}, 30-70 \%$ relative humidity, alternate 12 hours light and dark cycle, rabbit pellet feed and RO water ad libitum. Based on the health check-up done on the day of receipt of animals to the study personnel, all rabbits were adjudicated to be healthy.

\subsection{Study design}

All animals in the study were assigned to one of two treatment arms- either a single dose of BAK-Bimatoprost $(\mathrm{n}=28)$ or a TJM-bimatoprost ophthalmic solution $(\mathrm{n}=28)$. The preservative in the test arm was PHMB $(0.005 \%)$ as opposed to BAK (200 ppm) in the reference treatment arm. Treatment allocation was done in a non-randomized procedure, and each animal received the respective medication in both the eyes.

After the animals were received, they were acclimatized for one week before the study. On Day 0, animals were weighed, grouping was done and single dose $28 \mu \mathrm{L}$ of either the test or the reference medication was instilled into the cul-de-sac of each eye, using a positive displacement micropipette. Following administration of the single dose medication, animals were restrained for 1 minute in order to prevent eye rubbing. Animals were anaesthetized for aqueous humor collection using a mixture of ketamine (35 $\mathrm{mg} / \mathrm{kg}$; i.m) and xylazine $(5 \mathrm{mg} / \mathrm{kg}$; i.m). Time points for aqueous humor collection were $0.5,1,2,4,8,12$ and $24 \mathrm{Hrs}$ after drug administration, using $26^{1 / 2}$ needle in labeled (label included study number, animal ID, time point, treatment arm) micro centrifuge tubes.

In this study, categorization within the two treatment arms were done in two different ways: 1) aqueous humor time-point groups (7 groups in each treatment arm; every group made up of 4 animals equivalent to 8 eyes); 2) Eight pharmacokinetic (PK) cohorts. The aqueous humor time-point groups were constituted ( 8 eyes /time-point group) such that aqueous humor was collected from only one time-point group. i.e aqueous humor collected at 0.5 hrs post administration was drawn only from the group designated as $0.5 \mathrm{hr}$-time-point group. Similarly, other timepoint groups were designated based on the time of aqueous humor withdrawal for both treatment arms. Further, in each time-point group, the eyes were numbered from 1 to 8 , which formed the basis for assigning them to PK cohorts, described later.

Samples of aqueous humor collected were stored at $70^{\circ} \mathrm{C}\left( \pm 10^{\circ} \mathrm{C}\right)$ in deep freezer and measurement of drug concentrations for the reference and the test were done using Liquid chromatography-mass spectrometry (LCMS) analytical method. Lower limit of quantification was 0.05 $\mathrm{ng} / \mathrm{mL}$ and $0.250 \mathrm{ng} / \mathrm{mL}$ for bimatoprost and bimatoprost free acid respectively.
For analysis, PK parameters, such as maximum observed concentration (Cmax), time of observed Cmax (T_max), area under concentration-time curve from zero to time of last nonzero $\left(\mathrm{AUC}_{0-t}\right)$, area under the concentrationtime curve from zero to infinity-extrapolated $\left(\mathrm{AUC}_{0-i n f}\right)$ and elimination half-life ( $\mathrm{T}$ _Half) were calculated. As mentioned earlier, eyes were numbered from 1 to 8 in each time point group. Based on this numbering, animals were grouped into 8 PK cohorts: eye number 1 of all the seven time-point groups formed one evaluation PK cohort; similarly, eye number 2 of all the seven timepoint groups formed the second evaluation PK cohort and correspondingly, the same pattern was followed for constituting the remaining six PK cohorts within each treatment group. Statistical analysis of the pharmacokinetic parameters was done using a non-compartmental model. Descriptive statistics such as arithmetic mean, standard deviations and co-efficient of variation were computed using Nonlin software (version 5.1). While area under the curve was estimated using the log-linear trapezoidal method, half-life was estimated by linear regression of the concentration-time data. Since for each time point, measurements from only four animal were present, the data was pooled across different sub-groups to evaluate the PK parameters. For inferential statistics, analysis of variance (ANOVA) was applied and Bonferroni post-hoc tests were applied for comparison between groups.

\section{Results}

Bimatoprost is extensively metabolized in the rabbit eyes. In this study, bimatoprost concentration in both treatment arms was below the LLOQ in all the 8 eyes of the $2 \mathrm{hr}$-timepoint groups, which implied LLOQ was observed 2 hours post administration in both the treatment arms. Conversely, bimatoprost free acid was below the LLOQ in 6 out of 8 eyes in the $12 \mathrm{hr}$ - time-point group receiving TJM-bimatoprost and in all 8 eyes of the $12 \mathrm{hr}$-time-point group receiving BAK-bimatoprost, indicating that most of the LLOQ was observed 12-hours post administration in both treatment arms. Similar results to the free acid from were obtained when bimatoprost + bimatoprost free acid were combined and evaluated.

As described in the earlier section, for the PK analysis, the treatment groups were divided into 8 PK cohorts. In the study, results of the PK parameters pertaining to bimatoprost+ bimatoprost free acid concentration were as follows: Cmax was $11.93 \pm 2.7$ (Mean \pm SD) vs $10.92 \pm 3.84 \mathrm{ng} / \mathrm{ml}$, Tmax was $1.75 \pm 2.0$ vs $1.50 \pm$ $1.16 \mathrm{hr}$ and T_half was $2.13 \pm 0.58$ vs $2.47 \pm 0.79 \mathrm{hr}$ in the TJM- bimatoprost and BAK-bimatoprost treatment arms respectively. Other PK parameters are summarized in Table 1 and Table 2. The mean Cmax of 11.93 \pm 2.70 vs $10.92 \pm 3.84 \mathrm{ng} / \mathrm{ml}$ was comparable ( $\mathrm{P}>0.05$, one-way ANOVA) across TJM-bimatoprost and BAK-bimatoprost 
Table 1: Pharmacokinetic parameters of bimatoprost + bimatoprost free acid in TJM-bimatoprost arm after single ocular instillation in New Zealand rabbits, $n=7$

\begin{tabular}{|c|c|c|c|c|c|c|c|}
\hline Animal ID & $\begin{array}{c}\text { Dose } \\
\text { (mcg/eye) }\end{array}$ & Route & $\begin{array}{c}\text { Cmax } \\
(\mathrm{ng} / \mathrm{ml})\end{array}$ & $\begin{array}{c}\mathrm{AUC}_{0-t} \\
\left(\mathbf{h r}{ }^{*} \mathbf{n g} / \mathbf{m l}\right)\end{array}$ & $\begin{array}{l}\mathbf{A U C}_{0-i n f} \\
(\mathbf{h r} * \mathbf{n g} / \mathbf{m l})\end{array}$ & $\underset{\text { (hr) }}{\text { T_max }}$ & $\underset{\text { (hr) }}{\text { T_Half }}$ \\
\hline & 2.8 & Ocular & 15.48 & 48.93 & 49.89 & 2.00 & 2.05 \\
\hline & 2.8 & Ocular & 12.08 & 60.56 & 61.12 & 2.00 & 1.50 \\
\hline & 2.8 & Ocular & 10.46 & 43.76 & 46.46 & 1.00 & 1.84 \\
\hline \multirow[t]{12}{*}{$101-128$} & 2.8 & Ocular & 10.61 & 40.27 & _ & 2.00 & _ \\
\hline & 2.8 & Ocular & 9.33 & 35.53 & - & 2.00 & - \\
\hline & 2.8 & Ocular & 9.38 & 40.40 & - & 2.00 & - \\
\hline & 2.8 & Ocular & 16.54 & 63.23 & 63.49 & 2.00 & 3.05 \\
\hline & 2.8 & Ocular & 11.59 & 42.32 & 46.87 & 1.00 & 2.23 \\
\hline & & Mean & 11.93 & 46.88 & 53.56 & 1.75 & 2.13 \\
\hline & & Geomean & 11.69 & 46.00 & 53.08 & 1.68 & 2.07 \\
\hline & & Median & 11.10 & 43.04 & 49.89 & 2.00 & 2.05 \\
\hline & & SD & 2.70 & 10.02 & 8.13 & 0.46 & 0.58 \\
\hline & & Min & 9.33 & 35.53 & 46.46 & 1.00 & 1.50 \\
\hline & & Max & 16.54 & 63.23 & 63.49 & 2.00 & 3.05 \\
\hline & & $\mathrm{CV} \%$ & 22.66 & 21.39 & 15.18 & 26.45 & 27.14 \\
\hline
\end{tabular}

- Value not estimable

$\mathrm{AUC}_{0-\text { inf }}$, area under the concentration-time curve from zero to infinity-extrapolated; $\mathrm{AUC}_{0-t}$, area under concentration-time curve from zero to time of last nonzero; Cmax, maximum concentration; T_Half, elimination half life; T_max, time of observed Cmax

Table 2: Pharmacokinetic parameters of bimatoprost + bimatoprost free acid in BAK-bimatoprost after single ocular instillation in New Zealand rabbits, $n=7$

\begin{tabular}{|c|c|c|c|c|c|c|c|}
\hline \multirow[t]{4}{*}{ A.ID } & $\begin{array}{c}\text { Dose } \\
\text { (mcg/eye) }\end{array}$ & Route & $\begin{array}{c}\text { Cmax } \\
(\mathrm{ng} / \mathrm{ml})\end{array}$ & $\begin{array}{c}\mathbf{A U C}_{0-t} \\
(\mathbf{h r} * \mathbf{n g} / \mathbf{m l})\end{array}$ & $\begin{array}{l}\mathbf{A U C}_{0-i n f} \\
\left(\mathbf{h r} \mathbf{*}^{*} \mathbf{n g} / \mathbf{m l}\right)\end{array}$ & $\underset{(\mathbf{h r})}{\mathbf{T}_{-} \max }$ & $\underset{\text { (hr) }}{\mathbf{T}_{\text {hHalf }}}$ \\
\hline & 2.8 & Ocular & 9.92 & 45.95 & 46.33 & 1.00 & 3.31 \\
\hline & 2.8 & Ocular & 13.60 & 39.65 & - & 2.00 & - \\
\hline & 2.8 & Ocular & 8.36 & 29.98 & 31.41 & 1.00 & 1.89 \\
\hline \multirow[t]{12}{*}{$201-228$} & 2.8 & Ocular & 4.98 & 12.55 & _ & _ & _ \\
\hline & 2.8 & Ocular & 10.25 & 26.60 & 29.76 & $0 . \overline{5} 0$ & $2 . \overline{4} 9$ \\
\hline & 2.8 & Ocular & 9.32 & 25.82 & 26.60 & 0.50 & 1.48 \\
\hline & 2.8 & Ocular & 13.38 & 43.73 & 54.30 & 1.00 & 3.16 \\
\hline & 2.8 & Ocular & 17.55 & 49.81 & - & - & - \\
\hline & & Mean & 10.92 & 34.26 & 37.68 & 1.50 & 2.47 \\
\hline & & Geomean & 10.29 & 31.72 & 36.25 & 1.19 & 2.36 \\
\hline & & Median & 10.08 & 34.81 & 31.41 & 1.00 & 2.49 \\
\hline & & SD & 3.84 & 12.63 & 12.00 & 1.16 & 0.79 \\
\hline & & Min & 4.98 & 12.55 & 26.60 & 0.50 & 1.48 \\
\hline & & Max & 17.55 & 49.81 & 54.30 & 4.00 & 3.31 \\
\hline & & $\mathrm{CV} \%$ & 35.13 & 36.87 & 31.84 & 77.66 & 32.11 \\
\hline
\end{tabular}

- Value not estimable

$\mathrm{AUC}_{0-\text { inf }}$, area under the concentration-time curve from zero to infinity-extrapolated; $\mathrm{AUC}_{0-t}$, area under concentration-time curve from zero to time of last nonzero; Cmax, maximum concentration; T_Half, elimination half life; T_max, time of observed Cmax

treatment arms. Overall, there was no difference between TJM-bimatoprost and BAK-bimatoprost treatment arms in the PK end points.

\section{Discussion}

Bimatoprost, a prostaglandin analogue, acts via PG-F2 $\alpha$ receptors to decrease IOP by increasing the aqueous humor outflow. Although bimatoprost is a prodrug, the unchanged form can also have an equal efficacy as the active metabolite. Whether this action is exerted through
FP receptor dependent or independent pathways is still not clearly understood. Nevertheless, it is imperative to assess the concentration of the parent molecule as well as the free acid form when quantifying the pharmacokinetics of the molecule. ${ }^{23}$

In this study, the combined concentration of bimatoprost and bimatoprost free acid increased steadily and reached a peak between 1 to 2 hours post instillation of the drug in both treatment arms. The mean Cmax of $11.93 \pm$ 2.70 vs $10.92 \pm 3.84 \mathrm{ng} / \mathrm{ml}$ was comparable across TJM- 
bimatoprost and BAK-bimatoprost treatment arms. These results were agreeable with the Shen et al study ${ }^{24}$ wherein bimatoprost free acid Cmax for once daily innovator bimatoprost $0.01 \%$ was $13.9 \pm 1.8$. Howbeit, in contrast to the absolute values seen in our study, Ogundele ${ }^{25}$ reported a higher mean Cmax of $20.8 \pm 5.7 \mathrm{ng} / \mathrm{ml}$ and $45.8 \pm$ $14.3 \mathrm{ng} / \mathrm{ml}$ with innovator bimatoprost $0.01 \%$ and $0.03 \%$ respectively. However, the Tmax was similar in both studies, at around $1.5 \mathrm{hrs}$. The disparate results in Cmax between studies could be explained by the fact that New Zealand rabbits were used in Shen et al. ${ }^{24}$ and our study as compared to Dutch Belted rabbits used in the Ogundele study. Also, it is noteworthy to mention that the Ogundele study ${ }^{25}$ showed a significant higher aqueous humor concentration of innovator bimatoprost $0.03 \%$ compared to the lower strength $0.01 \%$ formulation.

Further, results of the PK parameters such as $\mathrm{AUC}_{0-t}$ and T_half were also comparable across the treatment arms. While $\mathrm{AUC}_{0-t}$ was $46.88 \pm 10.02 \mathrm{hr} * \mathrm{ng} / \mathrm{ml}$ in the TJM-bimatoprost arm, it was $34.26 \pm 12.63 \mathrm{hr} * \mathrm{ng} / \mathrm{ml}$ in the BAK-bimatoprost arm. In terms of T_Half, similar conclusions could be drawn: $2.13 \pm 0.58 \mathrm{hr}$ and 2.47 $\pm 0.79 \mathrm{hr}$ in the TJM-bimatoprost and BAK-bimatoprost arms respectively. The inter group geometric mean ratio was 1: 1.14, establishing concretely the similarity between the two formulations. Although $\mathrm{AUC}_{0-t}$ data is not available for innovator bimatoprost $0.01 \%, \mathrm{AUC}_{0-8}$ with bimatoprost free acid was reported as $42.8 \pm 3.1$ in the Shen et al study, ${ }^{24}$ which is comparable to the results of our study.

Our study results demonstrate that kinetics of the newer PHMB preservative containing TJM-bimatoprost ophthalmic solution is equivalent to BAK preservative containing Lumigan solution of lower strength. Using the new PHMB preservative in ophthalmic formulation has several advantages over BAK. Firstly, PHMB is less likely to cause adverse events such as conjunctival hyperaemia, eye irritation and pruritis because unlike BAK it is not a detergent preservative. Given an ideal situation, it would be tempting to do away with the use of a preservative all together, but it would come at a significant disadvantage of not having the utility of multi-dose usage. Therefore, using a preservative such as PHMB would be a prudent alternative compared to a corrosive preservative like BAK. Secondly, the proprietary GFR technology combines two water soluble polymers in a unique ratio resulting in multifold increase in viscosity without decrease in clarity and flow property. These properties mimic an artificial tear supplement and also stabilize the natural tear film. Thirdly, with the novel drug delivery system, there are two tight junction modulators. A synergistic effect of the combination would ensure an increase in mean residence time of bimatoprost, with a resultant increase in absorption leading to better penetration and distribution within the ocular tissue and ultimately induce the necessary action.

\section{Conclusion}

For the study reported here, the results taken in totality support the hypothesis that, in terms of pharmacokinetics, TJM-bimatoprost $0.01 \%$, containing PHMB preservative, is as effective as BAK-bimatoprost $0.01 \%$. However, further $\mathrm{PK}$ testing needs to be ascertained in human trials, as species difference between rabbits and human may lead to variation in the result. Moreover, the efficacy and safety of the new TJM-bimatoprost can only be established by conducting large multi-centre randomized clinical trial.

\section{Disclosures}

Arindam Halder, Vinod Buradeand Ajay J Khopade are employees of Sun Pharmaceutical Industries Limited. In line with Good Publication Practice (GPP3) guidelines ( http://www. ismpp.org/gpp3), the authors would like to thank Dr. Mohammed Shamil (M.D) for his medical writing assistance.

\section{Source of Funding}

None.

\section{Conflict of Interest}

None.

\section{References}

1. Quigley HA. The number of people with glaucoma worldwide in 2010 and 2020. $B r \quad J$ Ophthalmol. 2006;90(3):262-7. doi:10.1136/bjo.2005.081224.

2. Vijaya L, George R, Baskaran M, Arvind H, Raju P, Ramesh $\mathrm{SV}$, et al. Prevalence of Primary Open-angle Glaucoma in an Urban South Indian Population and Comparison with a Rural Population. Ophthalmology. 2008;115(4):648-54.e1. do1:10.1016/].0phtha.2007.04.062

3. Schmidl D, Schmetterer L, Garhöfer G, Popa-Cherecheanu A Pharmacotherapy of Glaucoma. J Ocul Pharmacol Ther. 2015;31(2):63-77. doi:10.1089/10p.2014.0067.

4. Sambhara D, Aref AA. Glaucoma management: relative value and place in therapy of available drug treatments. Ther Adv Chronic Dis.

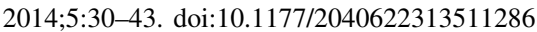

5. European Glaucoma Society. Terminology and guidelines for glaucoma. 3rd ed. Savona: Editrice DOGMA; 2008.

6. Williams RD, Cohen JS, Gross RL, Liu CC, Safyan E, Batoosingh AL. Bimatoprost Study Group. Long-term efficacy and safety of bimatoprost for intraocular pressure lowering in glaucoma and ocular hypertension: year 4. Br J Ophthalmol. 2008;92(10):1387-92.

7. Wirta D, Vandenburgh AM, Weng E, Whitcup SM, Kurstjens S, Beddingfield FC. Long-term safety evaluation of bimatoprost ophthalmic solution $0.03 \%$ : a pooled analysis of six double-masked, randomized, active-controlled clinical trials. Clin Ophthalmol 2011;5:759-65. doi:10.2147/opth.s17457

8. Chen YY, Wang TH, Liu C, Wu KY, Chiu SL, Simonyi S. Tolerability and efficacy of bimatoprost $0.01 \%$ in patients with open-angle glaucoma or ocular hypertension evaluated in the Taiwanese clinical setting: the Asia Pacific Patterns from Early Access of Lumigan 0.01 \% (APPEAL Taiwan) study. BMC Ophthalmol. 2016;16(1):162.

9. Steven DW, Alaghband P, Lim KS. Preservatives in glaucoma medication. $\quad B r \quad J$ Ophthalmol. 2018;102(11):1497-1503. 
do1:10.1136/bjophthalmol-2017-311544.

10. Myers J, Vold S, Zaman F, Williams J, Hollander D. Bimatoprost $0.01 \%$ or $0.03 \%$ in patients with glaucoma or ocular hypertension previously treated with latanoprost: two randomized 12-week trials. Clin Ophthalmol. 2014;8:643-52. doi:10.2147/opth.s59197.

11. Guenoun JM, Baudouin C, Rat P, Pauly A, Warnet JM. BrignoleBaudouin F. In vitro study of inflammatory potential and toxicity profile of latanoprost, travoprost, and bimatoprost in conjunctivaderived epithelial cells. Invest Ophthalmol Vis Sci. 2005;46(7):244450 .

12. Steven DW, Alaghband P, Lim KS. Preservatives in glaucoma medication. $\quad B r \quad J$ Ophthalmol. 2018;102(11):1497-1503. do1:10.1136/bjophthalmol-2017-311544.

13. Jaenen N, Baudouin C, Pouliquen P, Manni G, Figueiredo A, Zeyen T. Ocular Symptoms and Signs with Preserved and PreservativeFree Glaucoma Medications. Eur J Ophthalmol. 2007;17(3):341-9.

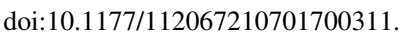

14. Pisella PJ. Prevalence of ocular symptoms and signs with preserved and preservative free glaucoma medication. $\mathrm{Br} J$ Ophthalmol. 2002;86(4):418-23. do1:10.1136/bj0.86.4.418.

15. Farshori P. Redistribution and Phosphorylation of Occludin During Opening and Resealing of Tight Junctions in Cultured Epithelial Cells.

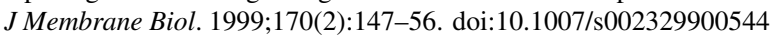

16. Findley MK, Koval M. Regulation and roles for claudin-family tight junction proteins. Wiley; 2009. Available from: https://dx.doi.org/10. 1002/iub.175. [0i:10.1002/iub. T75.

17. Ikeda $\mathrm{T}$, Ledwith $\mathrm{A}$, Bamford $\mathrm{CH}$, Hann RA. Interaction of a polymeric biguanide biocide with phospholipid membranes. Biochim et Biophys Acta. 1984;769(1):57-66. 101:0.10/0005 2736(84)90009-9.

18. Chadeau E, Dumas E, Adt I, Degraeve P, Noël C, Girodet C, et al. Assessment of the mode of action of polyhexamethylene biguanide against Listeria innocua by Fourier transformed infrared spectroscopy and fluorescence anisotropy analysis. Can J Microbiol. 2012;58(12):1353-61. 101:10س39/w2012-113.

19. Mashat BH. Polyhexamethylene biguanide hydrochloride: features and applications. Br J Environ Sci. 2016;4(1):49-55.

20. Larkin DFP, Kilvington S, Dart JKG. Treatment of Acanthamoeba Keratitis with Polyhexamethylene Biguanide. Ophthalmology.
1992;99(2):185-91. do1:10.1016/s0161-6420(92)31994-3.

21. Yet Castillo, Ernest J, Inventor; Alcon Laboratories Inc Inc., assignee. Sustained release and comfortable ophthalmic composition and method for ocular therapy. United States patent US 4,867,749. 2000 Apr 6.8 p. Int. Cl. A61F-00/18316.

22. Pereira S, Tettamanti M. Ahimsa and alternatives - the concept of the 4th R. The CPCSEA in India. ALTEX. 2005;22:3-6.

23. Woodward DF, Liang Y, Krauss AHP. Prostamides (prostaglandinethanolamides) and their pharmacology. $B r \quad J$ Pharmacol. 2008;153(3):410-9. doi:10.1038/sj.bjp.0707434.

24. Shen J, Goodkin ML, Tong W, Attar M. Ocular pharmacokinetics and tolerability of bimatoprost ophthalmic solutions administered once or twice daily in rabbits, and clinical dosing implications. Clin Ophthalmol. 2017;11:1761-7.

25. Ogundele A, Jasek MC. Aqueous humor penetration of topical bimatoprost $0.01 \%$ and bimatoprost $0.03 \%$ in rabbits. Clin Ophthalmol. 2010;4:1447-50. doi:10.2147/opth.s15521.

\section{Author biography}

Arindam Halder, Deputy General Manager

Vinod Burade, Senior General Manager

Ajay J Khopade, Vice-President

Monali Vakharia, Manager, Medical Affairs

Cite this article: Halder A, Burade V, Khopade AJ, Vakharia M. Aqueous humor pharmacokinetics of Benzalkonium chloride free bimatoprost formulated in tight junction modulation technology compared to Benzalkonium chloride preserved bimatoprost $0.01 \%$ ophthalmic solution in rabbit eyes. Indian J Clin Exp Ophthalmol 2021;7(2):321-326. 